\title{
REACTIONS WITH DISULPHUR MONOXIDE SOLUTIONS OBTAINED BY THE REDUCTION OF CUPRIC OXIDE BY ELEMENTAL SULPHUR
}

\author{
By S. R. Satyanarayana and A. R. Vasudeva Murthy \\ (Department of Inorganic and Physical Chemistry, Indian Institute of \\ Science, Bangalore-12, South India)
}

Received November 29, 1963

(Communicated by Prof. M. R. A. Rao, F.A.sc.)

\begin{abstract}
DisULPHUR monoxide is observed to be present in the products of combustion of elemental sulphur in oxygen at low pressures. ${ }^{1}$ A solution of the same oxide in carbontetrachloride is obtained by passing the products of such a combustion in the cooled solvent and pumping off the dissolved sulphur dioxide. ${ }^{2,3}$ Recently it has been shown that disulphur monoxide is also present along with sulphur dioxide in the products of reaction between elemental sulphur and certain metallic oxides at elevated temperature under vacuum. ${ }^{4}, 5$ When the products of such a reduction were bubbled through cooled carbontetrachloride $\left(-16^{\circ}\right)$, orange-yellow solution was obtained indicating the presence of the lower oxide of sulphur dissolved in the solvent. It was of interest to study the reactions of such solutions with several reagents which would characterise the nature of the sulphur compounds. Solutions in a few other inert solvents were also examined.
\end{abstract}

\section{EXPERIMENTAL}

About four grams of finely powdered cupric oxide (A.R. quality) was intimately mixed with twenty grams of resublimed sulphur and taken in a vertical combustion tube which was connected to a vacuum assembly through several traps fitted with appropriate ground glass joints. The combustion tube was heated in a vertical tubular furnace whose temperature could be regulated with the help of a variac. After the inset of the reaction, the products evolved were bubbled through a cooled inert organic solvent contained in one of the traps; any undissolved gaseous product was frozen in a subsequent trap cooled by liquid air.

The system was evacuated before heating the reaction mixture in the combustion tube. The combustion tube was gradually heated to $300-350^{\circ} \mathrm{C}$. 
and maintained at that temperature for about 30 minutes when the reduction of the metal oxide was complete. An orange-yellow solution was obtained during this interval while the products of combustion were being sucked through the solvent. The heating was stopped at the end of this period and the combustion tube was allowed to cool down while the vacuum pump was still running for about half an hour. Such a treatment was found to remove all the sulphur dioxide that might have dissolved in carbontetrachloride. This was confirmed in a separate experiment when all the sulphur dioxide dissolved in carbontetrachloride was expelled completely from solution on evacuation. The pump was stopped at the end of this interval and the vacuum was released under nitrogen. The solution was diluted three times with the same chilled solvent and aliquots of the clear orangeyellow solution were subjected to three following reactions to characterise the nature of the sulphur oxide present in the solution.

(1) Mercury decomposition, (2) Reduction by anhydrous hydrogen iodide and (3) Hydrolysis in an alkaline homogeneous medium. The experimental details for carrying out these reactions have been described earlier. ${ }^{1}$

(1) Decomposition of the orange-yellow solution with mercury.-Mercury is known to decompose sulphur rich oxides and liberate sulphur dioxide. The elemental sulphur set free during such a decomposition, reacts readily with mercury forming mercury sulphide. By estimating the sulphur dioxide and mercury sulphide produced during such a decomposition in the present investigation it was possible to compute the molecular complexity of the sulphur oxide.

The analytical results of a few representative experiments are presented in Table I and these results are found to be reproducible within the reasonable limits of experimental error.

The results of analysis show that for every gram atom of sulphur liberated as sulphur dioxide, there are three gram atoms of sulphur which form mercuric sulphide. The decomposition of the sulphur oxide present in the solution may be inferred to take place in terms of the equation

$$
2 \mathrm{~S}_{2} \mathrm{O}+\mathrm{Hg} \rightarrow 3 \mathrm{HgS}+\mathrm{SO}_{2} \text {. }
$$

It may thus be expected that the sulphur oxide contained in the yellowsolution of carbontetrachloride is practically pure disulphur monoxide.

(2) Reduction of the sulphur oxide in the orange-yellow solution by hydrogen iodide.-Anhydrous hydrogen iodide has been found to be a valuable reagent to characterise the nature of sulphur compounds. The oxygen in 
TABLE I

Mercury decomposition of the yellow solution (carbontetrachloride)

\begin{tabular}{ccccc}
\hline $\begin{array}{c}\text { Experi- } \\
\text { ment }\end{array}$ & $\begin{array}{c}\mathrm{HgS}^{*} \\
\text { formed }\end{array}$ & $\begin{array}{c}\mathrm{SO}_{2}{ }^{*} \\
\text { formed }\end{array}$ & $\begin{array}{c}\text { Total } \\
\text { sulphur }\end{array}$ & $\begin{array}{c}\text { Ratio of } \\
\text { elemental } \\
\text { sulphur } \\
\text { to sulphur } \\
\text { dioxide } \\
\mathrm{S}: \mathrm{SO}_{2}\end{array}$ \\
\hline 1 & 8.66 & 2.90 & 11.56 & 2.97 \\
2 & 7.47 & 2.44 & 9.91 & 3.06 \\
3 & 8.21 & 2.69 & 10.90 & 3.05 \\
\hline
\end{tabular}

* Both sulphide and sulphur dioxide are expressed in terms of $\mathrm{g}$. atom of sulphur $\times 10^{5}$

combination with sulphur is converted to water and corresponding to each atom of oxygen, two atoms of iodine are liberated. Sulphur is reduced to hydrogen sulphide and two atoms of iodine are set free for every molecule of hydrogen sulphide formed. By estimating hydrogen sulphide and iodine liberated during the reaction between hydrogen iodine and sulphur oxide, it was possible to determine the atomic ratios of sulphur and oxygen present in the compound dissolved in carbontetrachloride. The analytical results of a few typical experiments are presented in Table II.

\section{TABLE II}

Reaction between hydrogen iodide and sulphur oxide in carbon tetrachloride

\begin{tabular}{cccc}
$\begin{array}{c}\text { Experi- } \\
\text { ment }\end{array}$ & $\begin{array}{c}\mathbf{H}_{2} \mathbf{S}^{*} \\
\text { obtained }\end{array}$ & $\begin{array}{c}\text { Iodine obtained } \\
\text { in g. atom } \times 10^{5}\end{array}$ & $\begin{array}{c}\text { Ratio of Iodine } \\
\text { to sulphur }\end{array}$ \\
\hline 1 & 3.30 & 10.00 & 3.03 \\
2 & 3.33 & 9.98 & 3.00 \\
3 & 3.30 & 1.00 & 3.04 \\
\hline
\end{tabular}

* Hydrogen sulphide is expressed in terms of $g$. atoms of sulphur $\times 10^{5}$. 
It is seen from the results that for every gram mole of hydrogen sulphide formed, three gram atoms of iodine are liberated. Such a reaction can be represented in terms of the following equation

$$
\mathrm{S}_{2} \mathrm{O}+6 \mathrm{HI} \rightarrow 2 \mathrm{H}_{2} \mathrm{~S}+\mathrm{H}_{2} \mathrm{O}+6 \mathrm{I}
$$

wherein the sulphur in combination with oxygen is quantitatively converted into hydrogen sulphide. Thus the reduction reaction also indicates the sulphur oxide concerned is disulphur monoxide.

(3) Alkaline hydrolysis.-The hydrolytic reactions with the orange-yellow solution was carried out in a homogeneous medium as follows: 6 Forty-five milliliters of an aqueous solution of sodium hydroxide $(2 \mathrm{~N})$ was taken in a $500 \mathrm{ml}$. of stoppered conical flask, and $100 \mathrm{ml}$. of aldehyde free ethyl alcohol was added to it. To this solution was added an aliquot of the yellow solution $(5 \mathrm{ml}$.) and the mixture was shaken well, when a homogenized solution was obtained. The yellow colour of the disulphur monoxide solution disappeared quickly with the progress of the reaction. The products of reaction were found to be sulphide, sulphite and thiosulphate and they were estimated by the methods suggested by Kurtenacker and co-workers. ${ }^{7,8}$ Typical results of the alkaline hydrolysis are given in Table III.

TABLE III

Alkaline hydrolysis of sulphur oxide solution in carbontetrachloride

\begin{tabular}{ccccc}
\hline $\begin{array}{c}\text { Experi- } \\
\text { ments }\end{array}$ & $\begin{array}{c}\mathrm{S}^{=} \\
\text {formed }\end{array}$ & $\begin{array}{c}\mathrm{S}^{-} \mathrm{O}_{3}= \\
\text { formed }\end{array}$ & $\begin{array}{c}\mathrm{S}_{2} \mathrm{O}_{3}= \\
\text { formed }\end{array}$ & $\begin{array}{c}\text { Total } \mathrm{S}^{*} \\
\text { obtained }\end{array}$ \\
\hline 1 & 1.69 & $9 \cdot 24$ & 8.65 & $19 \cdot 58$ \\
2 & 1.99 & 10.9 & 10.2 & 23.09 \\
3 & 1.61 & 9.01 & 8.49 & $19 \cdot 11$ \\
\hline
\end{tabular}

* Compounds of sulphur expressed in terms of $g$. atom of sulphur $\times 10^{5}$.

The results of the present investigation show that the hydrolytic reaction of the sulphur oxide present in the yellow carbontetrachloride solution are similar to those of disulphur monoxide, ${ }^{6}$ disulphur dichloride, ${ }^{9}$ and dialkyl thiosulphates and tetraalhyl dithiodiamines. ${ }^{10}$ All these compounds have been looked upon as derivatives of the hypothetical thiosulphurous acid, $\mathrm{H}_{8} \mathrm{~S}_{2} \mathrm{O}_{2}$ formed as the primary product during the hydrolysis of the above 
compounds. Thiosulphurous acid has been known to give rise to sulphide, sulphite and thiosulphate during alkaline hydrolysis of its derivatives. It was therefore inferred that the yellow solution contained the anhydride of the thiosulphurous acid, viz., disulphur monoxide.

The results of the foregoing three independent reactions have furnished confirming. evidence to conclude that the lower oxide of sulphur dissolved in carbontetrachloride is disulphur monoxide which is produced as a result of the reduction of copper oxide by elemental sulphur. Copper sulphide is left behind in the residue.

Similar yellow solutions containing disulphur monoxide were also obtained in cooled toluene $\left(-90^{\circ} \mathrm{C}\right.$.) and anisole $\left(-25^{\circ} \mathrm{C}\right.$. $)$; however these solutions were contaminated with sulphur dioxide present along with disulphur monoxide produced by the reaction between elemental sulphur and copper oxide.

\section{SUMMARY}

When the products of reaction between elemental sulphur and copper oxide at elevated temperature in vacuum are bubbled through chilled inert organic solvents like carbontetrachloride, orange-yellow solutions were obtained indicating the presence of lower oxide of sulphur. This lower oxide has been found to be disulphur monoxide as shown by three different types of reactions; (1) Mercury decomposition, (2) Reaction with hydrogen iodide and hydrolytic reaction in an alkaline homogeneous medium.

\section{REFERENCES}

1. Vasudeva Murthy, A. R. .. Proc. Ind. Acad. Sci. 1952, 36, 388.

2. Rao, B. S.

.. Ibid., 1939, 10, 491.

3. Vasudeva Murthy, A. R. .. Ibid., 1952, 36, 425.

4.

.. Nature, 1962, 193, 773.

5. Satyanarayana, S. R. and Vasudeva Murthy, A. R.

Z. anorg. alegem. chem., 1963 (in press).

6. Ramachandran Nair, C. G. Can. Journ. Chem., 1963, 41, 898. and Vasudeva Murthy,

A. $\mathbf{R}$.

7. Kurtenacker, A. and $\quad . \quad Z$. 'anorg. Chem., 1927, 166, 177. Goldbach

8. Ramachandran Nair, C. G. Proc. Ind. Acad. Sci., 1962, 55, 168. and Vasudeva Murthy,

A. $\mathbf{R}$.

9.

10.

.. Z. Anorg. alegem. Chem., 1962, 318, 155. 